LA-UR-01-0094

Approved for public release; distribution is unlimited.

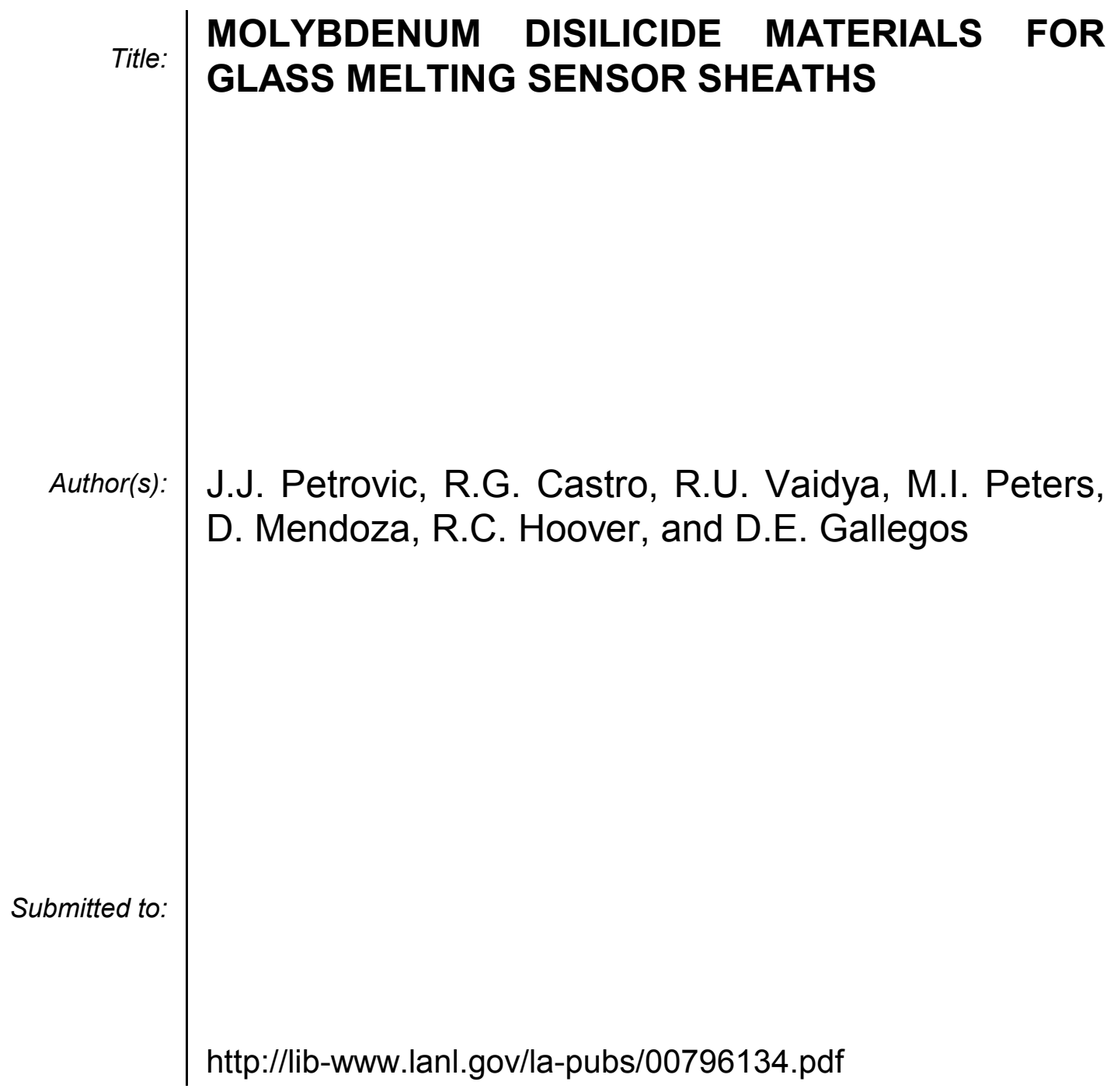

Los Alamos National Laboratory, an affirmative action/equal opportunity employer, is operated by the University of California for the U.S. Department of Energy under contract W-7405-ENG-36. By acceptance of this article, the publisher recognizes that the U.S. Government retains a nonexclusive, royaltyfree license to publish or reproduce the published form of this contribution, or to allow others to do so, for U.S. Government purposes. Los Alamos National Laboratory requests that the publisher identify this article as work performed under the auspices of the U.S. Department of Energy. Los Alamos National Laboratory strongly supports academic freedom and a researcher's right to publish; as an institution, however, the Laboratory does not endorse the viewpoint of a publication or guarantee its technical correctness. 


\section{MOLYBDENUM DISILICIDE MATERIALS FOR GLASS MELTING SENSOR SHEATHS}

J.J. Petrovic, R.G. Castro, R.U. Vaidya, M.I. Peters, D. Mendoza, R.C. Hoover, and D.E. Gallegos

Materials Science and Technology Division

Los Alamos National Laboratory

Los Alamos, NM 87545

\section{ABSTRACT}

Sensors for measuring the properties of molten glass require protective sensor sheaths in order to shield them from the extremely corrosive molten glass environment. $\mathrm{MoSi}_{2}$ has been shown to possess excellent corrosion resistance in molten glass, making it a candidate material for advanced sensor sheath applications. $\mathrm{MoSi}_{2}$-coated $\mathrm{Al}_{2} \mathrm{O}_{3}$ tubes, $\mathrm{MoSi}_{2}-\mathrm{Al}_{2} \mathrm{O}_{3}$ laminate composite tubes, and $\mathrm{MoSi}_{2}-\mathrm{Al}_{2} \mathrm{O}_{3}$ functionally graded composite tubes have been produced by plasma spray-forming techniques for such applications.

\section{INTRODUCTION}

The glass industry has a critical need for advanced sensors that can determine properties of molten glass such as temperature, viscosity, and chemistry. Because molten glass is a very corrosive high temperature environment, sensors placed in molten glass must be protected by sensor sheaths that are corrosion-resistant to molten glass. Materials that are presently used for direct exposure to molten glass are noble metals such as platinum, refractory metals such as molybdenum, and refractory ceramics such as AZCS (Alumina-Zirconia-Chromia-Silica).

For thermocouple protection sheaths, the glass industry currently uses either platinum tubes or platinum-coated alumina tubes for thermocouples that are inserted through the glass-air line. While platinum is a corrosion-resistant material above, at, and below the glass line, it is very expensive and its expense is a constraining factor on the extent of its use. Molybdenum sheaths can be employed for thermocouples that are completely immersed in molten glass, but not for thermocouples that traverse the glass-air line, due to the poor oxidation resistance of molybdenum. While refractory ceramics such as AZCS possess good molten glass corrosion-resistance above, at, and below the glass line, these materials are difficult to fabricate into long and narrow thermocouple protection sheath tubes. Additionally, AZCS has very low strength and can exhibit extensive plastic deformation at elevated temperatures.

$\mathrm{MoSi}_{2}$-based materials show excellent molten glass corrosion-resistance both above and below the glass line. Unlike platinum, $\mathrm{MoSi}_{2}$ materials are inexpensive 
and can be readily fabricated into protective sheath tubular geometries by industrial processes such as plasma spraying. In addition, the elevated temperature strength of $\mathrm{MoSi}_{2}$ materials is significantly higher than that of the refractory ceramics. $\mathrm{MoSi}_{2}$ is also electrically conductive, while the refractory ceramics are insulator materials.

Because of their combination of properties, $\mathrm{MoSi}_{2}$-based materials constitute an important new class of materials for glass industry sensor sheath applications.

\section{MOLTEN GLASS CORROSION RESISTANCE OF $\mathrm{MoSi}_{2}$}

The molten glass corrosion-resistance of $\mathrm{MoSi}_{2}$ has been characterized in an alkali borosilicate glass (1). The corrosion behavior of $\mathrm{MoSi}_{2}$ in comparison to the refractory ceramic AZCS is shown in Figure 1, for locations above, below, and at the glass-air line. The corrosion-resistance of $\mathrm{MoSi}_{2}$ is similar to that of AZCS both above and below the glass-line, but at the glass-air line $\mathrm{MoSi}_{2}$ has a lower corrosion-resistance than AZCS by approximately a factor of five.
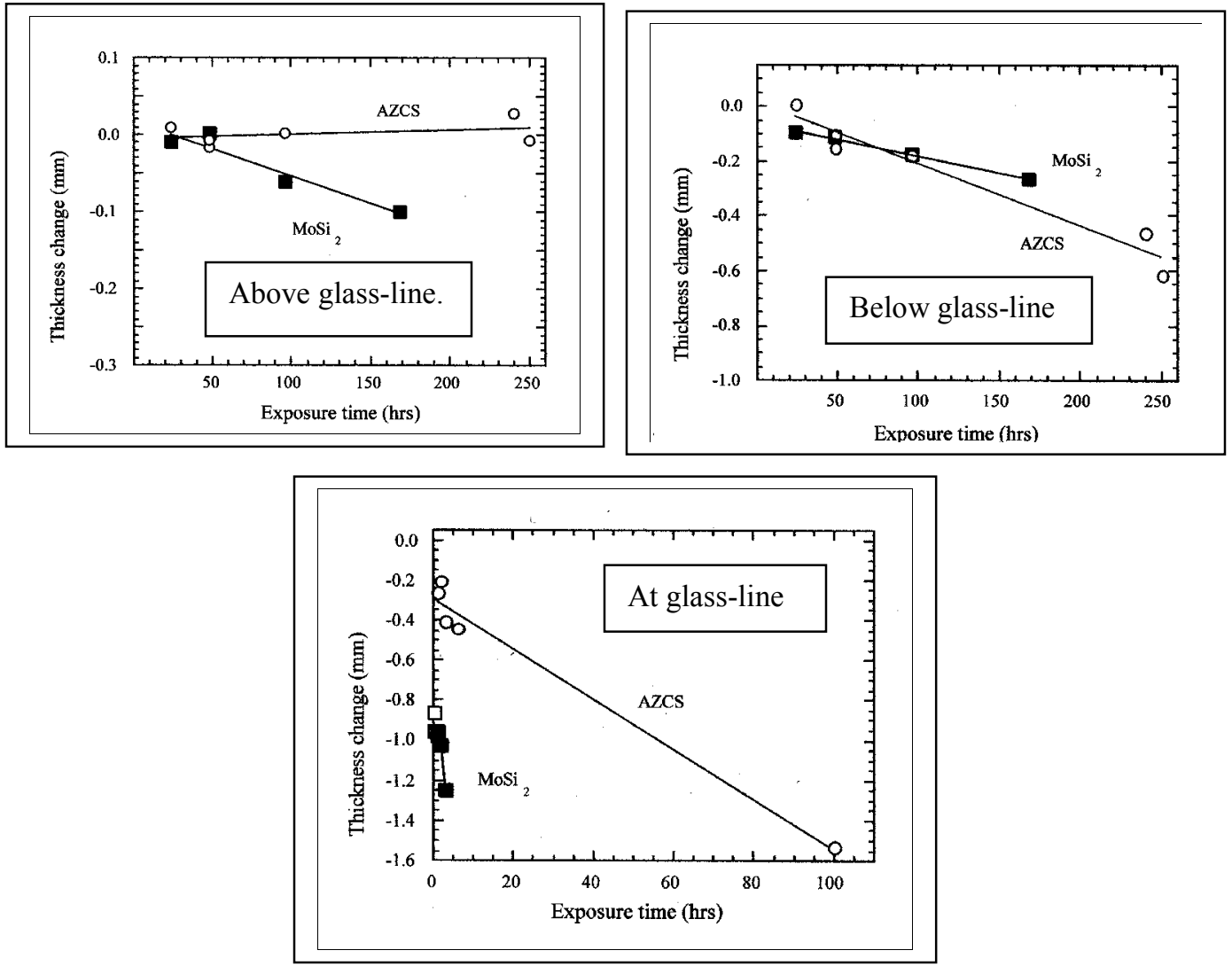

Figure 1: Molten glass corrosion of $\mathrm{MoSi}_{2}$ above, below, and at the glass-air line (1). 
Figure 2 shows the corrosion mechanisms that occur for $\mathrm{MoSi}_{2}$ when it is immersed in molten glass. Above the glass-line a protective $\mathrm{SiO}_{2}$ layer forms, while below the glass-line a complex multiphase protective layer is formed. However, at the glass-line no protective layer forms. Hence, the corrosion rate of $\mathrm{MoSi}_{2}$ is maximum at the glass-line. For any material that is immersed in molten glass, the maximum corrosion rate occurs at the glass-line due to the increased chemical activity and mechanical convection at this location.

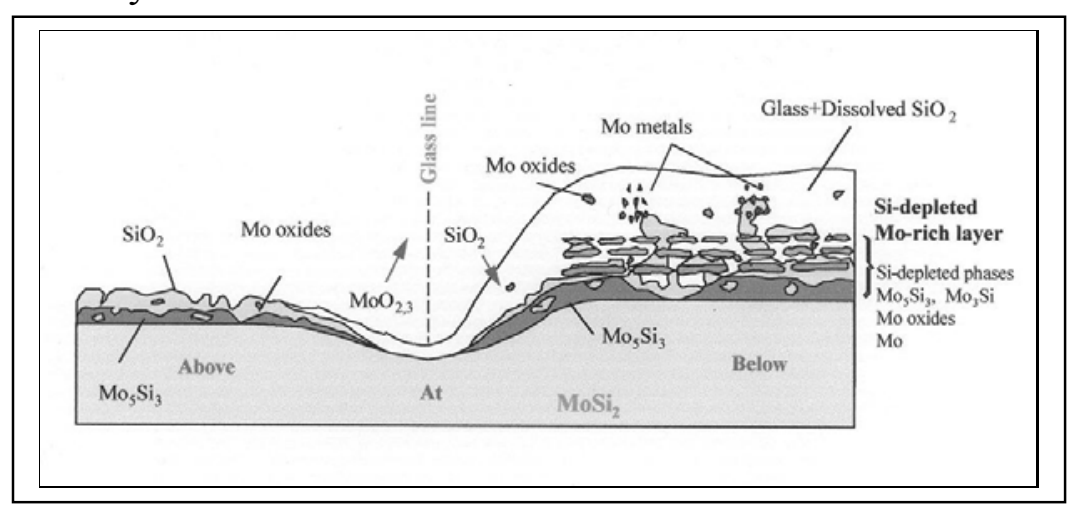

Figure 2: Corrosion mechanisms of $\mathrm{MoSi}_{2}$ in molten alkali borosilicate glass (1).

\section{$\mathrm{MoSi}_{2}$-COATED $\mathrm{Al}_{2} \mathrm{O}_{3}$ TUBES}

Sensor sheaths for glass furnace temperature sensors and for other types of furnace sensors such as video monitoring systems operating inside the glass furnace require a tubular geometry for the sensor sheath. $\mathrm{MoSi}_{2}$-based tubes can be readily fabricated by plasma spray-forming (2). In this process, $\mathrm{MoSi}_{2}$ or composites based on $\mathrm{MoSi}_{2}$ are plasma sprayed onto graphite or alumina tubes.

$\mathrm{MoSi}_{2}$ and $\mathrm{Al}_{2} \mathrm{O}_{3}$ constitute a good composite system for such applications, since these materials are thermodynamically stable with each other at elevated temperatures, and possess matching thermal expansion coefficients that minimize thermal stresses. $\mathrm{MoSi}_{2}-\mathrm{Al}_{2} \mathrm{O}_{3}$ composites may exhibit improved thermal shock resistance, which is desirable for sensor sheath applications.

Advanced plasma spray techniques were employed to place $\mathrm{MoSi}_{2}$ coatings on commercial $\mathrm{Al}_{2} \mathrm{O}_{3}$ tubes. A Miller thermal spraying system (SG $100 \mathrm{Gun}$ and two Model 1264 programmable hoppers) coupled to a Fanuc robotic system (S-10), an in-flight particle analyzer (Technar DPV 2000), and an infrared camera (Mikron TH 5104) were employed to fabricate the $\mathrm{MoSi}_{2}$-coated $\mathrm{Al}_{2} \mathrm{O}_{3}$ tubes.

A photo of a $\mathrm{MoSi}_{2}$-coated $\mathrm{Al}_{2} \mathrm{O}_{3}$ tube is shown in Figure 3. The $\mathrm{Al}_{2} \mathrm{O}_{3}$ was a commercially available closed-end tube (998 alumina from LSP Industrial Ceramics Inc.) with an OD of $12.7 \mathrm{~mm}$ and an ID of $9.53 \mathrm{~mm}$. The tube was 
coated with a $2 \mathrm{~mm}$ thick coating of $\mathrm{MoSi}_{2}$, over a $450 \mathrm{~mm}$ length of the tube, including the closed end. A cross-section of the coated tube is also shown in Figure 3.
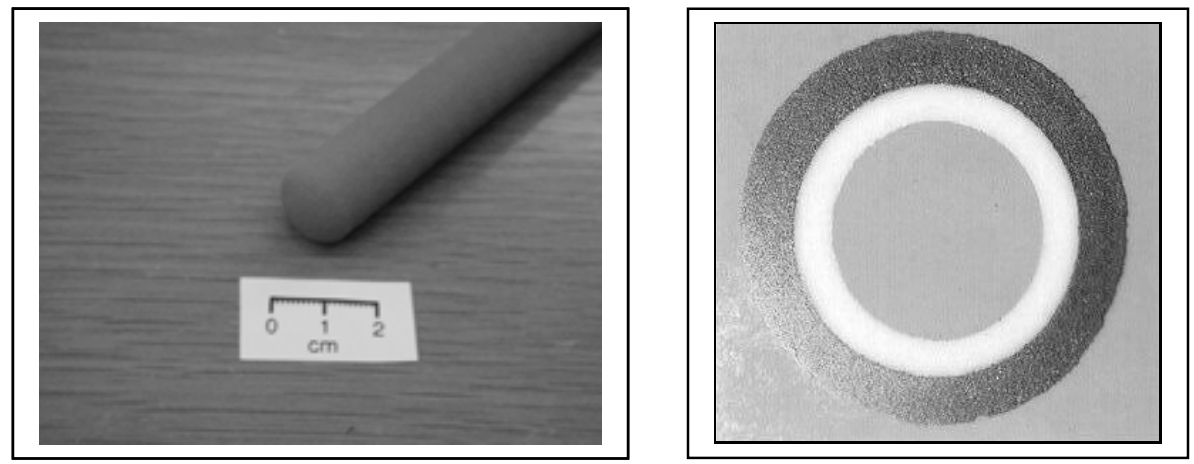

Figure 3: $\mathrm{MoSi}_{2}$-coated $\mathrm{Al}_{2} \mathrm{O}_{3}$ closed-end tube. Tube cross-section is also shown.

\section{$\mathrm{MoSi}_{2}-\mathrm{Al}_{2} \mathrm{O}_{3}$ LAMINATE COMPOSITE TUBES}

Figure 4 shows the cross-sections of laminate $\mathrm{MoSi}_{2}-\mathrm{Al}_{2} \mathrm{O}_{3}$ tubes that were fabricated by plasma spraying alternate layers of $\mathrm{MoSi}_{2}$ and $\mathrm{Al}_{2} \mathrm{O}_{3}$ onto a graphite tube mandrel (the graphite mandrel is subsequently removed by oxidation).

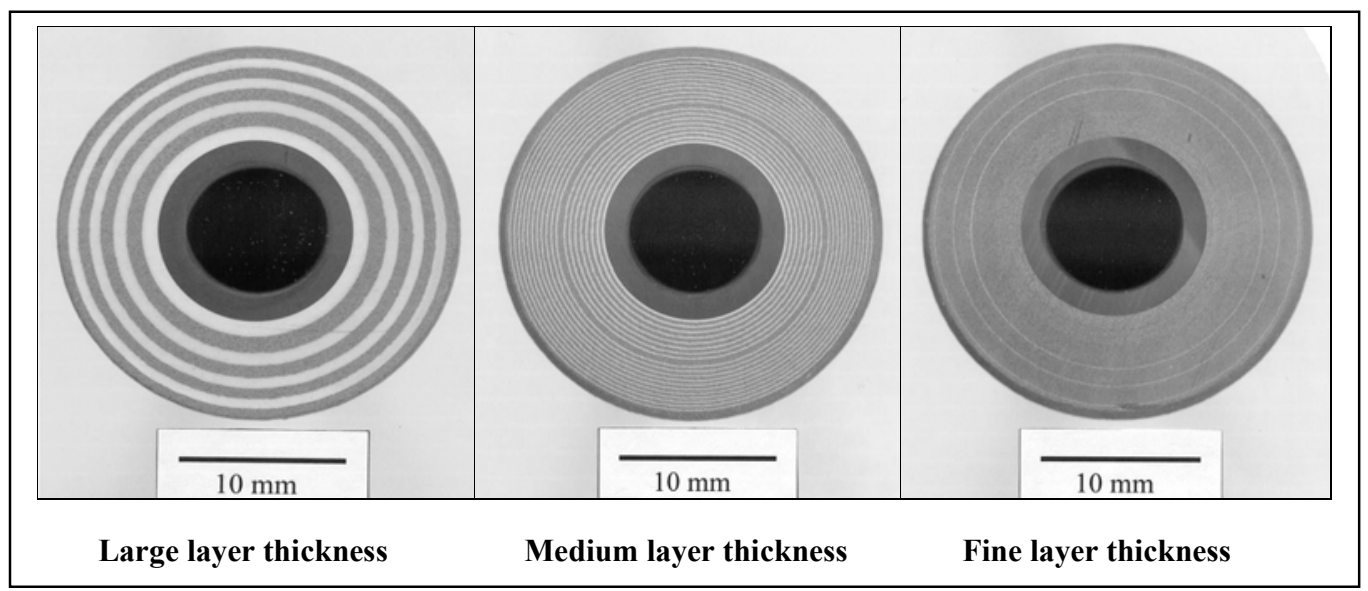

Figure 4: 50 vol. $\% \mathrm{MoSi}_{2}-50$ vol. $\% \mathrm{Al}_{2} \mathrm{O}_{3}$ laminate composite tubes produced by plasma spray-forming. $\mathrm{MoSi}_{2}$ is the dark phase and $\mathrm{Al}_{2} \mathrm{O}_{3}$ the light phase.

Tubes with three different layer thicknesses of $0.8 \mathrm{~mm}, 0.2 \mathrm{~mm}$, and $0.08 \mathrm{~mm}$ were fabricated. The fabricated tubes were approximately $300 \mathrm{~mm}$ in length. Because of the thermal expansion coefficient match between $\mathrm{MoSi}_{2}$ and $\mathrm{Al}_{2} \mathrm{O}_{3}$, no 
cracking due to thermal stresses has occurred in the tubes. $\mathrm{MoSi}_{2}-\mathrm{Al}_{2} \mathrm{O}_{3}$ laminate composite bend strengths were in the range of 85-115 $\mathrm{MPa}$ and were observed to increase with decreasing layer thickness.

\section{$\mathrm{MoSi}_{2}-\mathrm{Al}_{2} \mathrm{O}_{3}$ FUNCTIONALLY GRADED COMPOSITE TUBES}

Figure 5 shows the cross-sections of functionally graded $\mathrm{MoSi}_{2}-\mathrm{Al}_{2} \mathrm{O}_{3}$ tubes fabricated by plasma spray-forming. Both continuously graded and layered graded tubes were fabricated. The strengths of these FGM tubes were approximately $70 \mathrm{MPa}$.

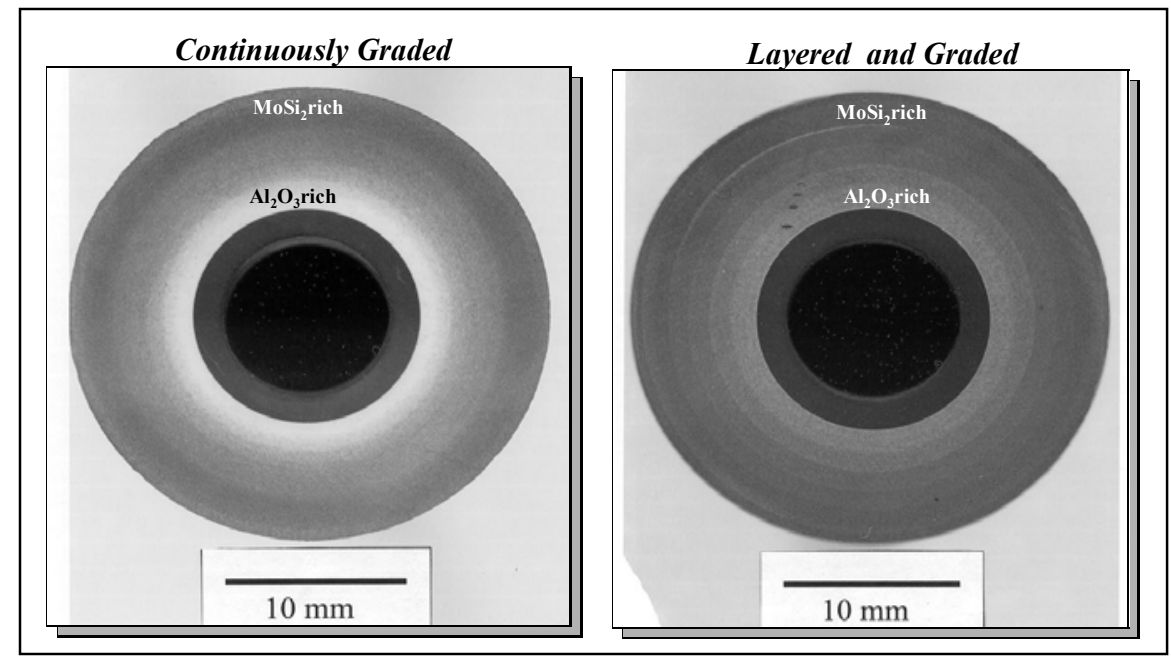

Figure 5: Continuously graded and layered graded $\mathrm{MoSi}_{2}-\mathrm{Al}_{2} \mathrm{O}_{3}$ composite tubes produced by plasma spray-forming.

The $\mathrm{MoSi}_{2}-\mathrm{Al}_{2} \mathrm{O}_{3}$ functionally graded materials exhibited interesting loaddisplacement curves when mechanically loaded in C-ring test specimen configurations as shown in Figure 6.
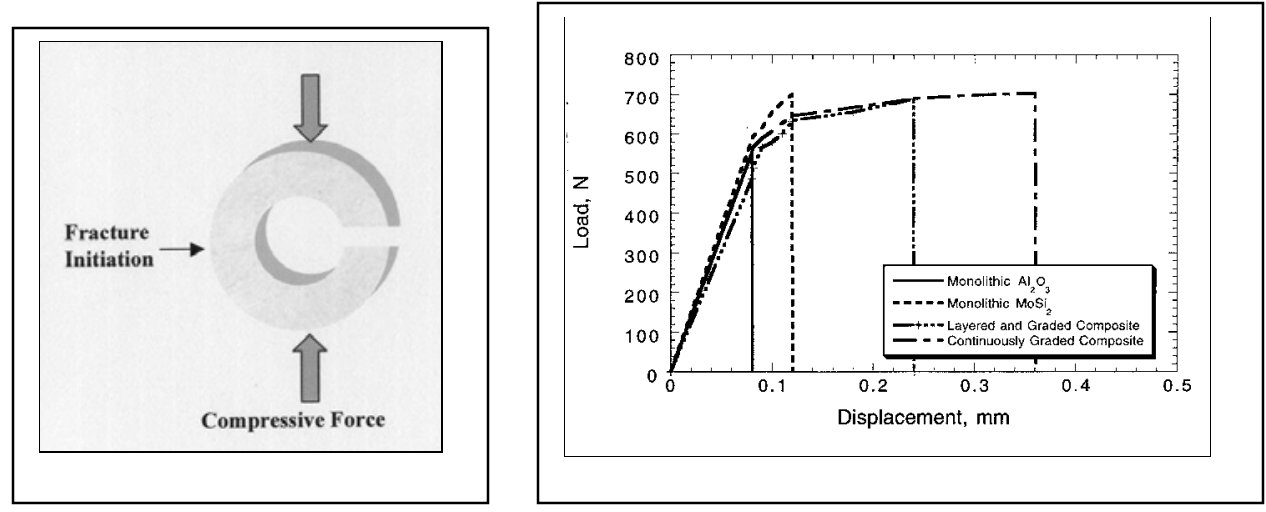
Figure 6: C-ring mechanical test load-displacement curves for $\mathrm{MoSi}_{2}-\mathrm{Al}_{2} \mathrm{O}_{3}$ functionally graded composite tubes.

Monolithic $\mathrm{MoSi}_{2}$ and $\mathrm{Al}_{2} \mathrm{O}_{3}$ tubes showed relatively low work-of-fracture values (the work-of-fracture is the area under the load-displacement curve). The value for $\mathrm{MoSi}_{2}$ was $496 \mathrm{~J} / \mathrm{m}^{2}$, while that for $\mathrm{Al}_{2} \mathrm{O}_{3}$ was $285 \mathrm{~J} / \mathrm{m}^{2}$. In distinct contrast to these monolithic values, the layered graded composite showed a work-of-fracture of $766 \mathrm{~J} / \mathrm{m}^{2}$, while the continuously graded $\mathrm{MoSi}_{2}-\mathrm{Al}_{2} \mathrm{O}_{3}$ composite showed a work-of-fracture of $955 \mathrm{~J} / \mathrm{m}^{2}$.

The substantial increase in the work-of-fracture of the functionally graded $\mathrm{MoSi}_{2}-\mathrm{Al}_{2} \mathrm{O}_{3}$ composites in comparison to the work-of-fracture values of monolithic $\mathrm{MoSi}_{2}$ and $\mathrm{Al}_{2} \mathrm{O}_{3}$ correlated with fracture surface observations. In the functionally graded composites, fracture initiated from the outside $\mathrm{MoSi}_{2}$ region of the tube and then proceeded into the graded two-phase structure. As it did so, the fracture surface transitioned from smooth to rough, indicating significant crack deflection and greater energy absorption during the fracture process through the graded microstructure.

\section{SUMMARY}

$\mathrm{MoSi}_{2}$ is a material that is resistant to molten glass corrosion. This makes it a candidate material for sensor protection sheaths, such as thermocouple sensors, that are immersed in molten glass. Advanced plasma spray techniques were employed to produce tubular sheaths configurations. $\mathrm{MoSi}_{2}$-coated $\mathrm{Al}_{2} \mathrm{O}_{3}$ tubes, $\mathrm{MoSi}_{2}-\mathrm{Al}_{2} \mathrm{O}_{3}$ laminate tubes, and $\mathrm{MoSi}_{2}-\mathrm{Al}_{2} \mathrm{O}_{3}$ functionally graded tubes were fabricated. Functionally graded tubes exhibited significantly higher work-offracture values than monolithic tubes.

\section{REFERENCES}

1. Y.S. Park, D.P. Butt, R. Castro, J. Petrovic, and W. Johnson, "Durability of Molybdenum Disilicide in Molten Alkali Borosilicate Glass", Materials Science and Engineering, A261, 278-283 (1999).

2. A.H. Bartlett, R.G. Castro, D.P. Butt, H. Kung, J.J. Petrovic, Z. Zurecki, "Plasma Sprayed $\mathrm{MoSi}_{2} / \mathrm{Al}_{2} \mathrm{O}_{3}$ ", Industrial Heating, January 1996. 